\title{
Gallbladder Disorders Detected by Ultrasound
}

\author{
Hamad Elniel H. Eltyib, Adel M. Al-Garni, Saddig D. Jastaniah* \\ Department of Diagnostic Radiology, Faculty of Applied Medical Sciences, King Abdulaziz University, Jeddah, KSA \\ Email: sjastaniah@kau.edu.sa
}

Received 22 April 2014; revised 21 May 2014; accepted 23 June 2014

Copyright (C) 2014 by authors and Scientific Research Publishing Inc.

This work is licensed under the Creative Commons Attribution International License (CC BY).

http://creativecommons.org/licenses/by/4.0/

(c) (i) Open Access

\begin{abstract}
Patients who have disease of the biliary tract commonly present with acute right upper quadrant pain, nausea or vomiting, mid-epigastric pain, and/or jaundice. Etiologies include inflammation with or without infection, noninflammatory disorders, and benign or malignant neoplasms of the gallbladder or bile ducts. Ultrasound (US) is now accepted as the initial imaging modality of choice for the work-up of suspected biliary tract disease. A retrospective study was carried out at King Abdulaziz University Hospital to discuss the protocol of ultrasound scanning in demonstrating incidence and complication of Gall-bladder (GB) pathologies. Known cases of GB pathologies (100 patients) were surveyed by ultrasound using spatial digital iU22 Philips Convex probe $3.5 \mathrm{MHz}$. All patients were evaluated with ultrasonogphy following the international scanning guidelines and protocols. The age of the patients is between $(9-90)$ years, 68 Patients $(68 \%)$ were females and 32 patients (32\%) were males. Range of age group of accumulation for gallstone presence was (35 - 50) years in females and above 50 years in males. Incidence of gallbladder pathologies are $59 \%$ (female $46 \%$ and $13 \%$ male). Incidence of gallstone is $37 \%$, and ratio of incidence is between male to female 1:3. Other pathologies of gallbladder were found to be acute cholecystities $12 \%$, chronic cholocystities $5 \%$, sludge $2 \%$, carcinoma of the Gall-bladder 1\%, Gall-bladder polyps $1 \%$ and Emphysematous choleycystities $1 \%$. Ultransonography is a single imaging modality sufficient for evaluation of patient with suspected gallbladder pathologies (gallstone) which can provide information about the presence of gallstone and more over about site and cause of biliary tract obstruction. Ultrasound is highly sensitive and specific means for diagnosis of the gallbladder disorders.
\end{abstract}

\section{Keywords}

Gallbladder, Ultrsound, Stones

${ }^{*}$ Corresponding author. 


\section{Introduction}

Diseases of the liver usually cause upper abdominal pain either acute or chronic. Abdominal pain can also result from abnormalities in gall bladder, kidneys, pancreas, stomach, duodenum, spleen... etc. [1]. All these conditions can be diagnosed easily via sonographic procedure. Other cases cannot be properly diagnosed with ultrasound such as uncomplicated peptic ulcer disease, acute myocardial infarction and basal pneumonitis [2].

Ultrasound is the first imaging test used for detection of gallbladder and bile duct abnormalities. This test is non-invasive, uses no dyes, and is not painful. Ultrasound produces good images of the small ducts in the liver and the higher part of the major bile duct [3].

Ultrasonography is the most helpful imaging modalities used for the diagnosis of gallstone disease. It is safe, rapid, and relatively inexpensive and involves no radiation exposure. It is the image of choice for patients with suspected biliary colic. Positive findings include stones, thickening of the gallbladder wall, pericholecystic [4].

A common disorder is Gallbladder stones and is usually asymptomatic. Some patients show biliary colic, and often severe pain in the epigastrium or right upper quadrant, and sometimes between the scapula due to temporary obstruction of the cystic duct with a gallstone. In case the cystic duct obstruction persists, the patient may develop cholecystitis [5].

The presence of cholecystitis was best diagnosed by ultrasound; images normally indicate the presence of gallstones, pericholecystic fluid and a thickened wall of gallbladder. In cases with symptomatic gallstones and a negative ultrasound examination, endoscopic ultrasound may be helpful [6].

Tumors occurring in gallbladder are either benign or malignant. Papillomas, adenomyomas, or cholesterol polyps are associated with benign tumors. Whereas malignant tumors are uncommon, cholecystectomy for patients with polyps larger than $10 \mathrm{~mm}$ seems warranted [7].

If gall-bladder is not detected, scan with high resolution and frequency linear or linear array transducers is mandatory. This minimizes missing tiny gallstones, especially in the funds of the superficial Gallbladder [8].

This measurement includes the mucosa, smooth muscle of its wall, liver capsule and any tissue between the liver and Gall-bladder. The normal measurements are taken in the transverse rather than longitudinal plane to avoid any possibility of thickening due to measuring in an off-axis plane. The normal appearing wall is not routinely measured [8] [9].

The present study was designed to see the frequency and occurrence of different types of GB pathologies and to evaluate the accuracy of ultrasonography for diagnosis of different gallbladder disorders.

\section{Material and Method}

A cross section observation study done at the diagnostic radiology department at King Abdulaziz University Hospital (KAUH). We collected data of patients subjective to US of gallbladder. 100 patients referred to the ultrasound departments for abdominal ultrasound either symptomatic or asymptomatic subjected to ultrasound using different types of ultrasound units with $3.5 \mathrm{MHz}$ and $5 \mathrm{MHz}$ curve linear probes. Spatial digital iU22 Philips Convex probe 3.5 Data analysis performed using the tables and computerized systems.

\section{Results}

The age or the patients is between (9 - 90) years (Table 1 and Figure 1) 68 Patients (68\%) were females and 32 patients (32\%) were males (Table 2 and Figure 2). Range of age group of accumulation for gallstone presence was (35 - 50) years in females and above 50 years in male.

The causes for examination for normal case among 41 patients enrolled in the study was collected in Table 3 and Figure 3. Comparing between stone case, other abnormal cases and normal cases among 100 patients enrolled in the study (Figure 4). Comparing between stone case and other abnormal cases and showing the percentage of stone cases among 59 patients enrolled in the study (Figure 5) where the incidence of gallbladder pathologies are 59\% (female $46 \%$ and $13 \%$ male). Incidence of gallstone $37 \%$. The ratio of incidence between male to female 1:3 as shown in Figures 6-8. Other pathologies of gallbladder were found to be acute cholecystities $12 \%$, chronic cholocystities $5 \%$, sludge $2 \%$, carcinoma of the Gall-bladder $1 \%$ and Gall-bladder polyps $1 \%$. Emphysematous choleycystities 1\%.

All abnormal cases, sex and age distribution compared with post cholecystectomy and showing the Percentage of post cholecystectomy among 59 patients enrolled in the study as shown in Tables 4-6 and Figures 9-12. 
Table 1. Age groups distribution through 100 patients for Gall bladder pathology ultrasound investigation enrolled in the study.

\begin{tabular}{cccc}
\hline Age & All & Female & Male \\
\hline $0-9$ & 3 & 3 & 0 \\
$10-19$ & 6 & 4 & 2 \\
$20-29$ & 14 & 10 & 4 \\
$30-39$ & 19 & 11 & 9 \\
$40-49$ & 26 & 17 & 5 \\
$50-59$ & 15 & 10 & 2 \\
$60-69$ & 10 & 8 & 2 \\
$70-79$ & 5 & 3 & 0 \\
$80-89$ & 1 & 1 & 0 \\
$90-$ more & 1 & 1 & 32 \\
Total & 100 & 68 & \\
\hline
\end{tabular}

Table 2. Distribution of sex \& normality groups among 100 patients enrolled in the study.

\begin{tabular}{cccc}
\hline & Both & Normal & Abnormal \\
\hline All patients & 100 & 41 & 59 \\
Female & 68 & 22 & 46 \\
Male & 32 & 19 & 13 \\
\hline
\end{tabular}

Table 3. Distribution groups causes for exam for normal case among 41 patients enrolled in the study.

\begin{tabular}{ccc}
\hline Causes & No. \\
\hline Fatty liver & 8 \\
Liver metastasis & 2 \\
High liver enzymes & 2 \\
Hepatomegaly & 2 \\
Hepatitis & 2 \\
RUQ Pain & 17 \\
Other cancer metastasis & 2 \\
Jaundice & 2 \\
Post sleeve surgery & 2 \\
Liver cyst & 1 \\
\hline
\end{tabular}

Table 4. The details of other abnormality among 22 patients enrolled in the stud.

\begin{tabular}{|c|c|c|c|}
\hline Other abnormality & $\operatorname{sex}$ & age & Causes of exam \\
\hline Wall thickening & $\mathrm{F}$ & 52 & Cholangiocarcinoma \& Follow up \& evaluation of stent \\
\hline Enlarge gallbladder with mass & M & 45 & Cholangiocarcinoma \& cheek biliary tree \\
\hline Hepatic cyst make occlusion & M & 35 & hydatid liver \\
\hline Pericholecystic edema & $\mathrm{F}$ & 9 & Hepatomegaly \\
\hline Gallbladder not well distended & $\mathrm{F}$ & 6 & Hepatomegaly \& jaundice \\
\hline Wall thickening & M & 46 & CLD 2ed to HBV for $\mathrm{f} / \mathrm{u}$ \\
\hline Slightly contracted & $\mathrm{F}$ & 47 & RUQ pain + R/O gallstone \\
\hline Acute acalculouscholecystitis & $\mathrm{F}$ & 93 & high liver enzyme \& obstructive jaundice \\
\hline Sludge & M & 57 & $\begin{array}{l}\text { Jaundice \& multiple myeloma \& high liver function test (LFT) } \\
\text { \& bone marrow transfusion }\end{array}$ \\
\hline
\end{tabular}


Table 5. Age groups distribution through 100 patients for Gall bladder pathology ultrasound Investigation.

\begin{tabular}{|c|c|c|c|c|c|c|c|c|c|c|c|c|}
\hline \multirow{2}{*}{ Groups } & \multicolumn{10}{|c|}{ Age groups distribution through 100 patients for Gall bladder pathology ultrasound investigation } & \multicolumn{2}{|c|}{ Total cases } \\
\hline & $0-9$ & $10-19$ & $20-29$ & $30-39$ & $40-49$ & $50-59$ & $60-69$ & $70-79$ & $80-89$ & 90 - more & Number & Percentage \\
\hline 1 & 0 & 4 & 7 & 10 & 8 & 4 & 5 & 3 & 0 & 0 & 41 & 41 \\
\hline 2 & 1 & 2 & 4 & 8 & 9 & 7 & 3 & 2 & 1 & 0 & 37 & 37 \\
\hline 3 & 0 & 0 & 1 & 3 & 5 & 3 & 2 & 0 & 0 & 0 & 14 & 14 \\
\hline 4 & 2 & 0 & 0 & 1 & 3 & 2 & 0 & 0 & 0 & 0 & 8 & 8 \\
\hline total & 3 & 6 & 12 & 22 & 25 & 15 & 10 & 5 & 1 & 1 & 100 & 100 \\
\hline
\end{tabular}

Table 6. Sex groups distribution through 100 patients for Gall bladder pathology ultrasound investigation.

\begin{tabular}{|c|c|c|c|c|}
\hline \multirow{2}{*}{ Groups } & \multicolumn{2}{|c|}{ Sex } & \multicolumn{2}{|c|}{ Total } \\
\hline & Male & Female & Number & Percentage \\
\hline 1 & 19 & 22 & 41 & 41 \\
\hline 2 & 6 & 31 & 37 & 37 \\
\hline 3 & 4 & 10 & 14 & 14 \\
\hline 4 & 3 & 5 & 8 & 8 \\
\hline Total & 32 & 68 & 100 & 100 \\
\hline
\end{tabular}

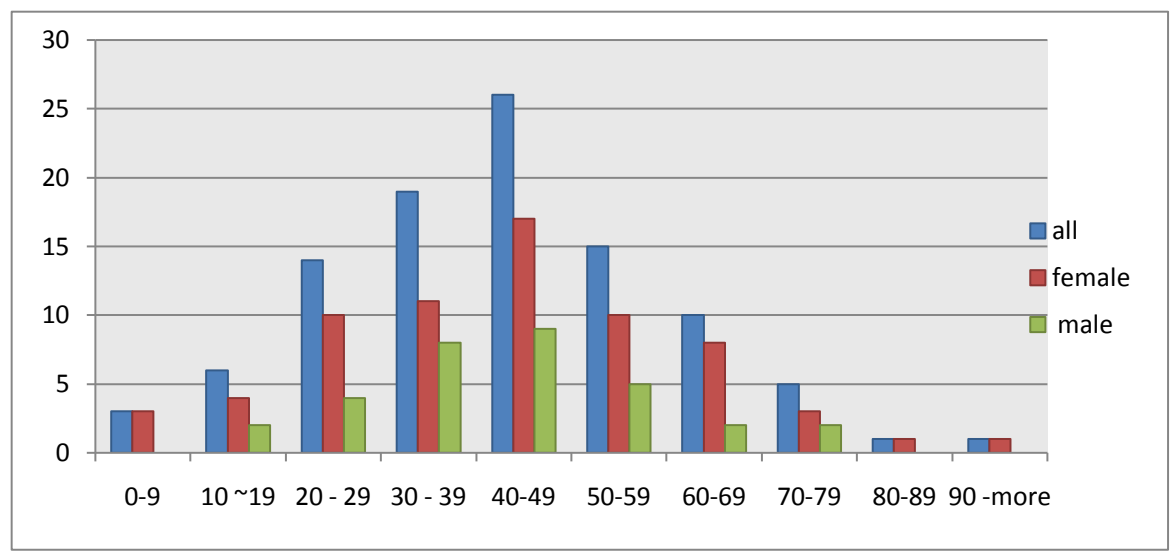

Figure 1. Distribution of sex and age groups among 100 patients enrolled in the study.

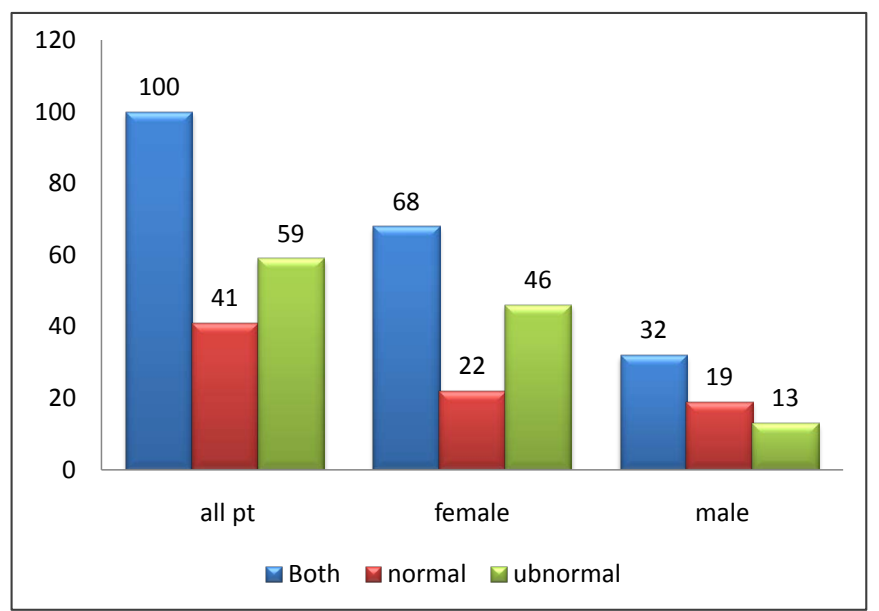

Figure 2. Distribution of sex \& normality groups among 100 patients enrolled in the study. 


\section{Causes for exam for normal case}

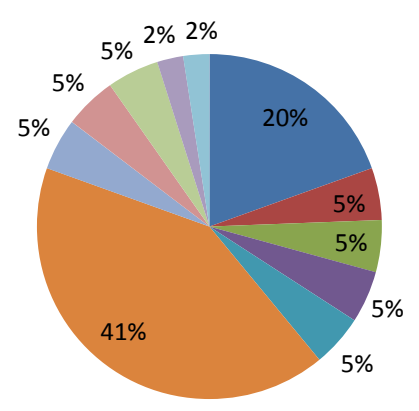

- fatty liver

- liver metastasis

wigh liver enzymes

- hepatomegaly

nepatitis

nUQ Pain

- other cancer metastasis

maundice

post sleeve surgery

- liver cyst

- HIV

Figure 3. Distribution groups causes for exam for normal case among 41 patients enrolled in the study.

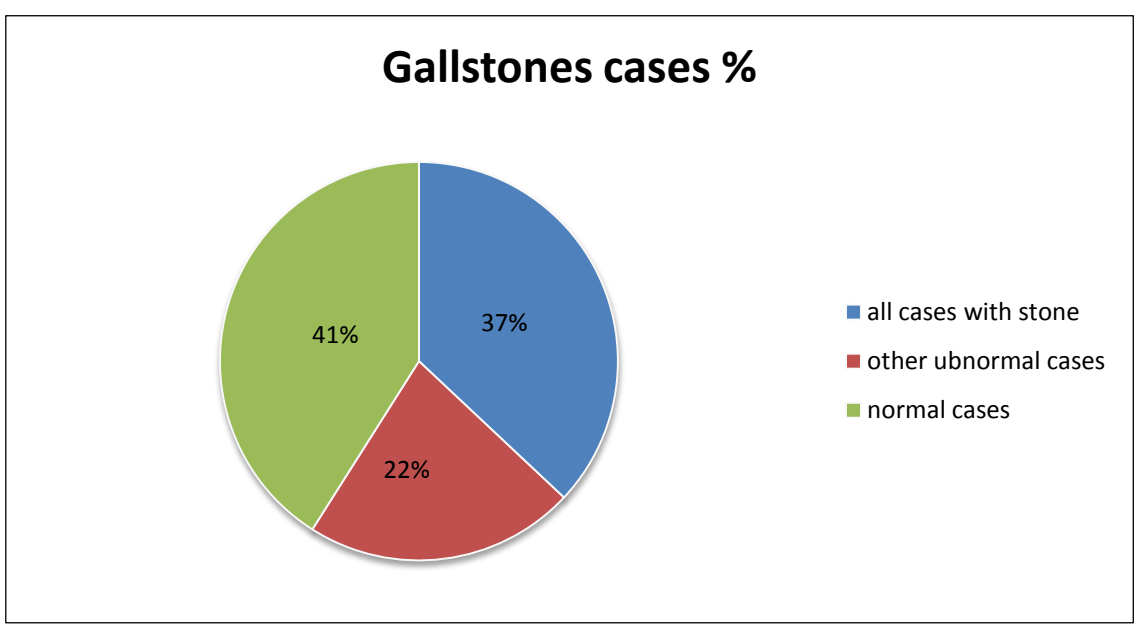

Figure 4. Comparing between stone case, other abnormal cases and normal cases among 100 patients enrolled in the study.

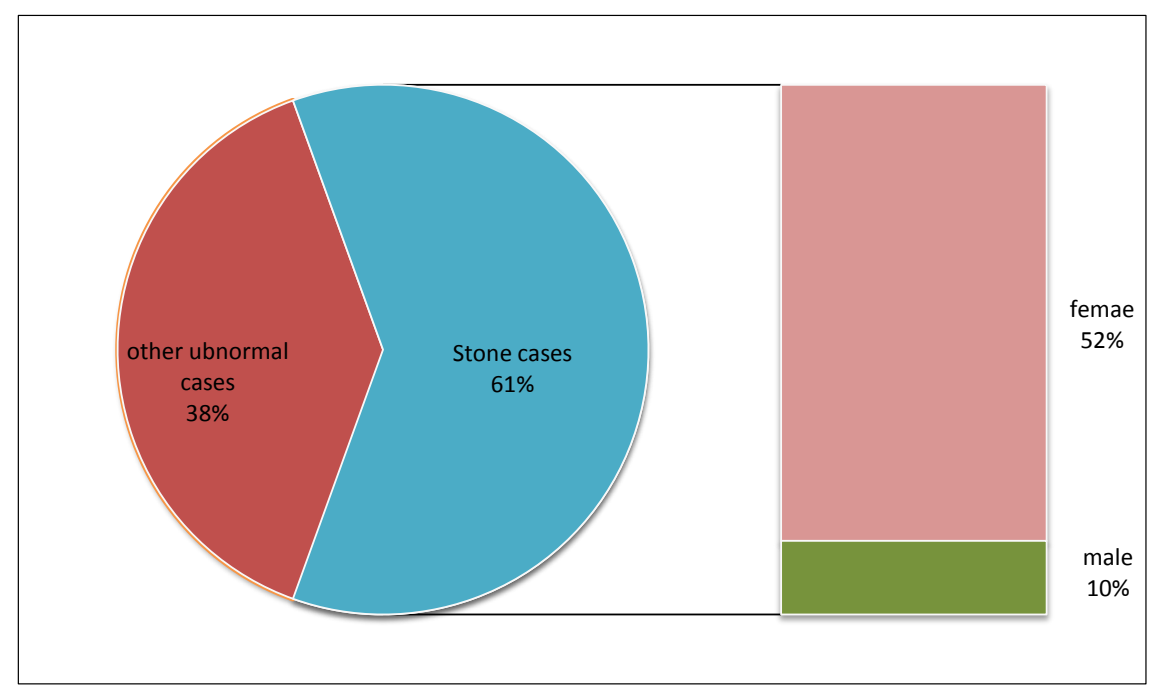

Figure 5. Comparing between stone case and other abnormal cases and showing the percentage of stone cases among 59 patients enrolled in the study. 


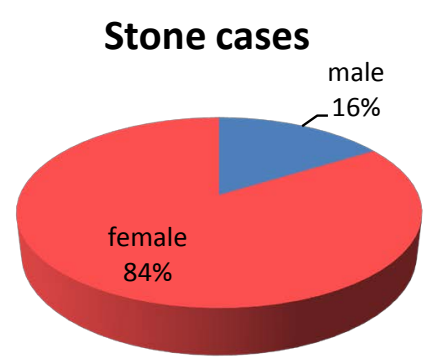

Figure 6. Distribution of sex groups among 37 patients with stone enrolled in the study.

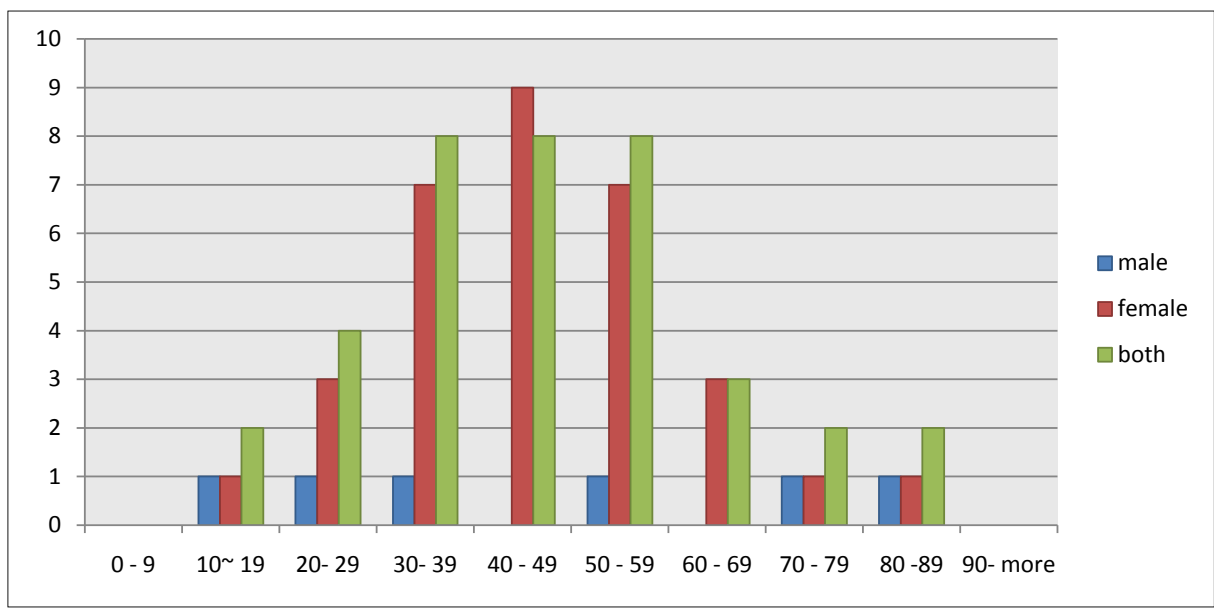

Figure 7. Distribution of stone cases sex and age groups among 37 patients enrolled in the study.

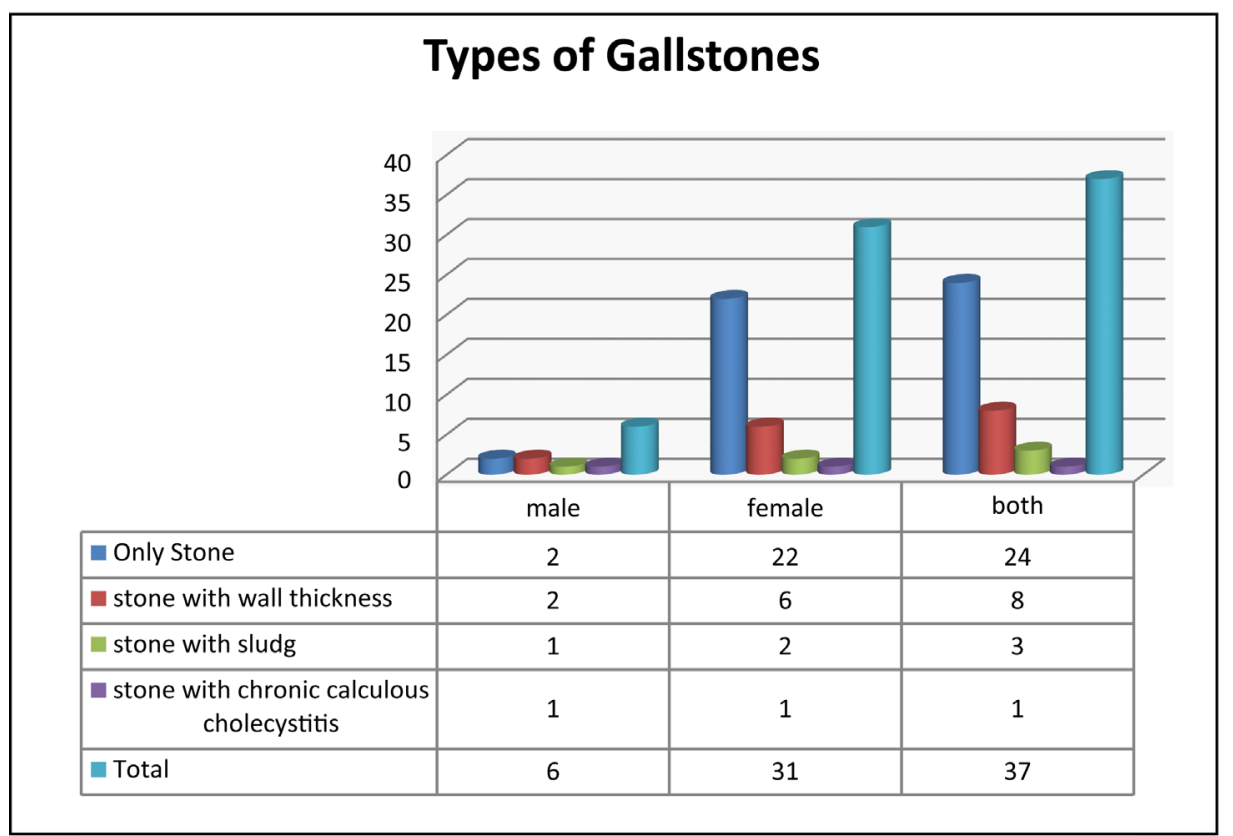

Figure 8. Distribution of type of stone cases age groups among 37 patients enrolled in the study. 


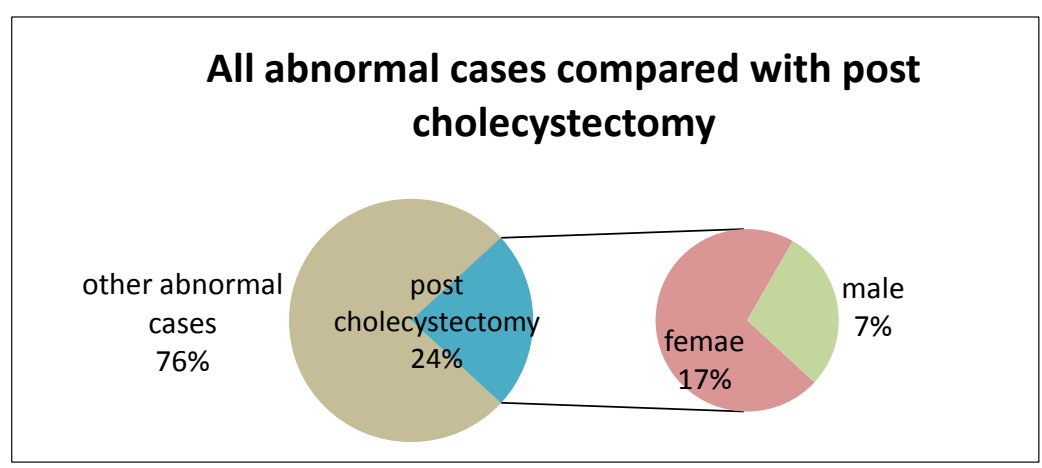

Figure 9. All abnormal cases compared with post cholecystectomy and showing the percentage of post cholecystectomy among 59 patients enrolled in the study.

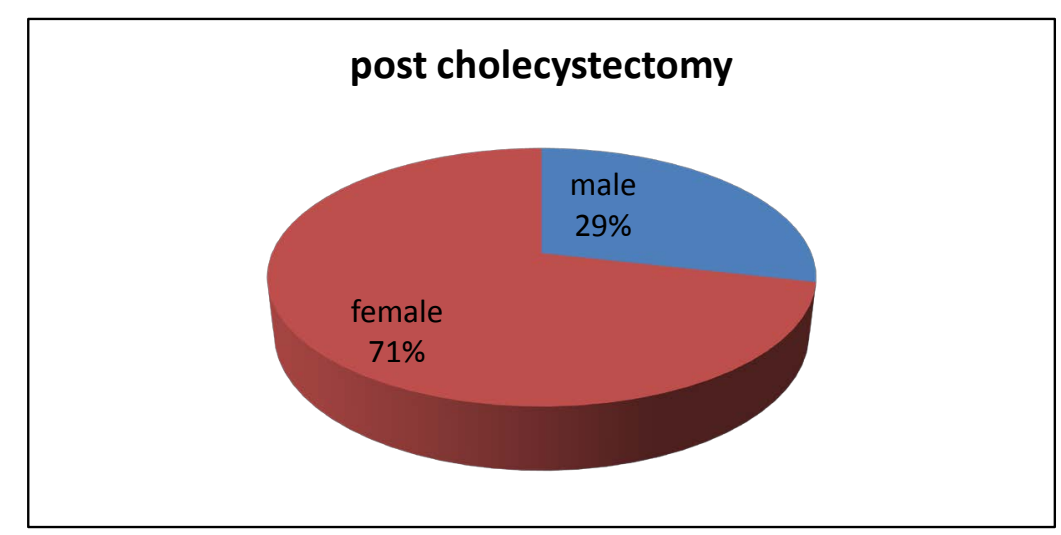

Figure 10. Distribution of sex groups among 14 patients with post cholecystectomy enrolled in the study.

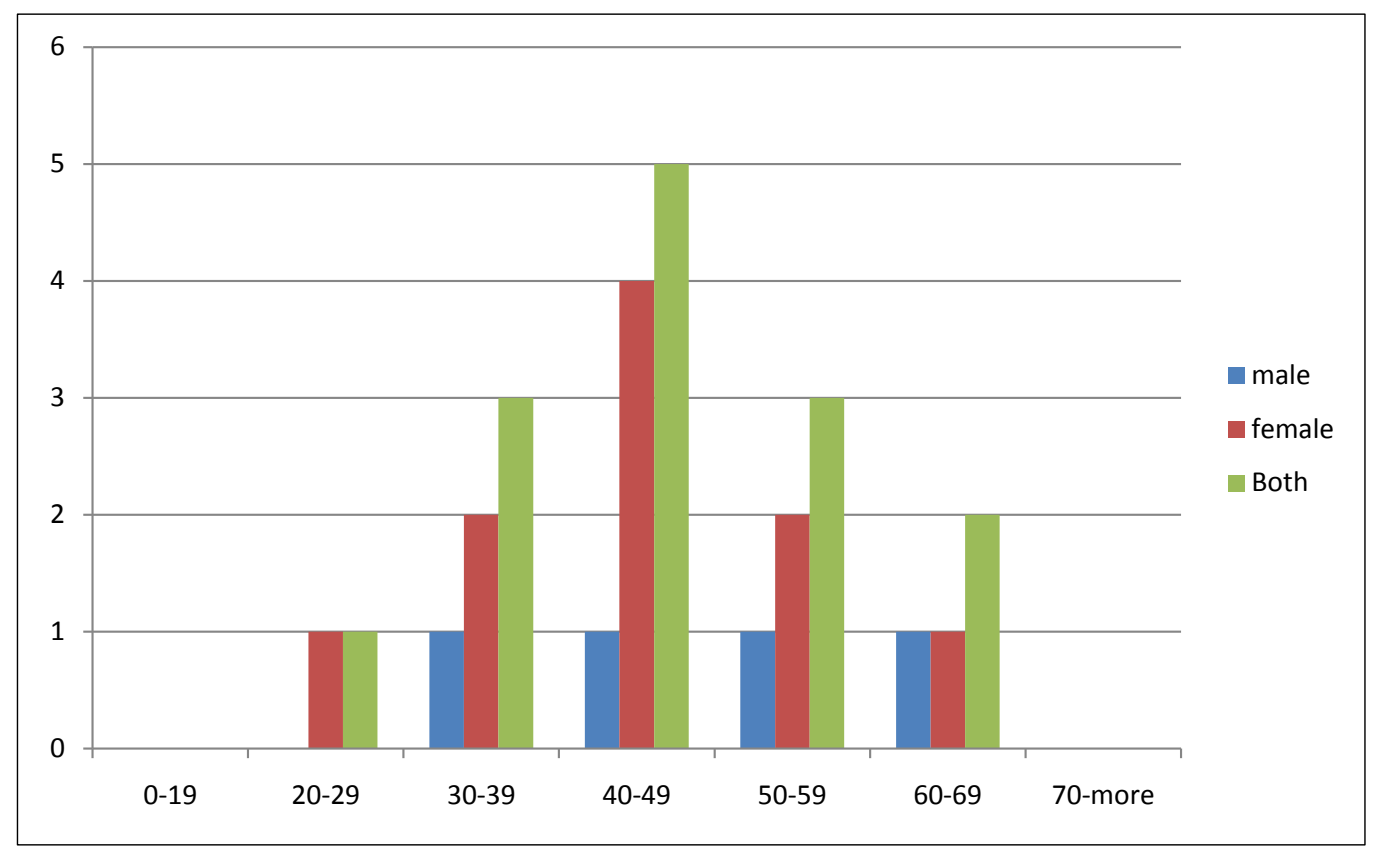

Figure 11. Distribution of post cholecystectomy sex and age groups among 14 patients enrolled in the study. 


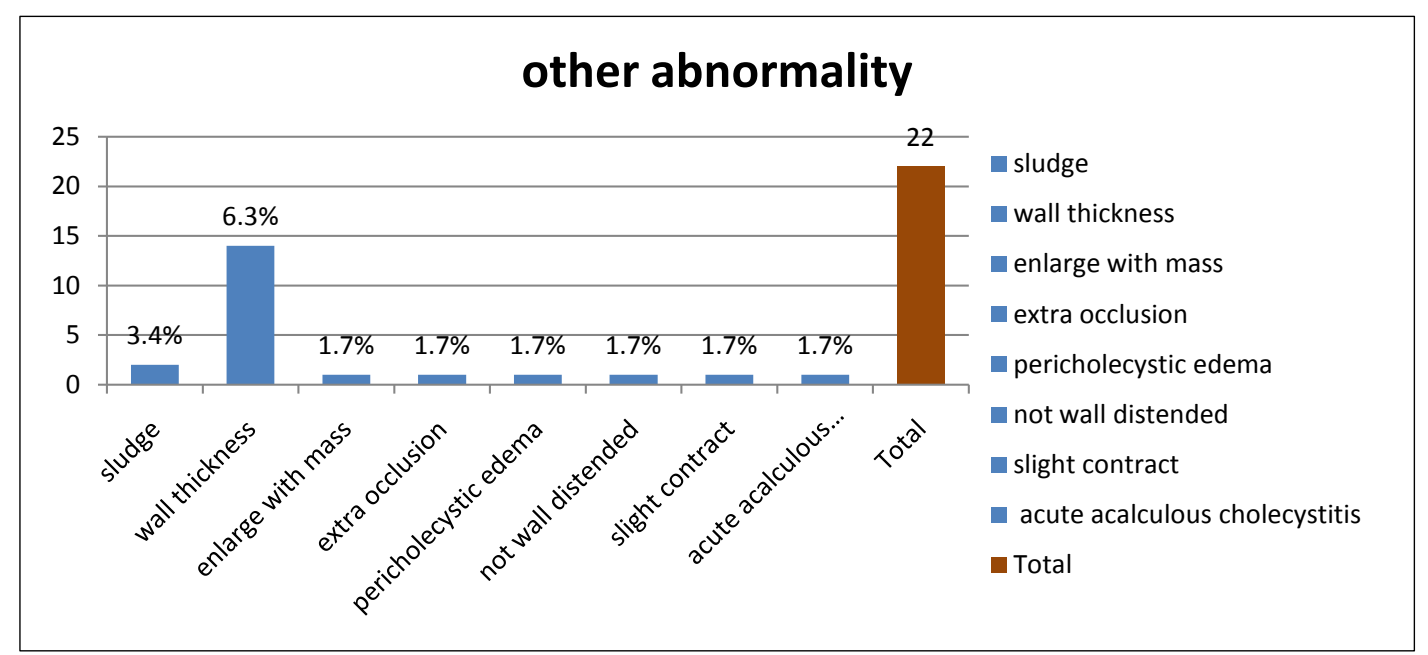

Figure 12. Percentage of other abnormality among 22 patients enrolled in the study. Group 1 = normal cases; Group 2 = gallstone; Group 3 = cholecystectomy; Group 4 = Miscellaneous.

\section{Discussion}

The gallbladder was found to be an ideal organ for sonography, the procedure is more cost effective, the diagnostic accuracy is said to be high (95\%). From the gallbladder diseases which have characteristic appearance with ultrasound: cholecystitis either acalculous or calculous which shows intensive echoes with obvious posterior shadows. Tumors appear as a mass within the gallbladder or as a diffuse shadow along the wall [8].

Although $10 \%$ to $15 \%$ of people developed gallstones, lower than half of those with gallstones have symptoms, fewer than $10 \%$ developed potentially life-threatening complications. One of the commonest complaints is upper abdominal pain, and in majority of the cases the aetiology is treatable [10]. Abdominal pain is a common problem in all ages. In a previous study, range of age group of accumulation for gallstone presence was 35 - 50 years in females and more than 50 years in male that are readily visible with ultrasonography [11].

Ultrasonography plays a key role in the diagnosis of gall bladder and biliary diseases. In acute cholecystitis, the gall bladder is distended, thick walled and tender, may show calculi and pericholecystic fluid collection [12]. Whereas, in chronic cholecystitis the gall bladder is smaller than usual, with many stones and has thick fibrous echogenic wall. Ultrasonography is considered an important tool for diagnosing obstructive jaundice and locating the level and cause of obstruction.

In the present study the incidence of gallbladder pathologies are $59 \%$ (women $46 \%$ and $13 \%$ men) while gallbladder disease affects $8 \%$ of men and $17 \%$ of women in the United States resulting in over 600,000 surgeries each year [1] [2]. Cholecystitis, the most common emergent surgical condition of the gallbladder, is diagnosed in up to $10 \%$ of total patients and $21 \%$ of elderly patients presenting to the emergency department with acute abdominal pain [1].

Overall, biliary tract disease is the 3rd most common cause of acute abdominal pain admitted to the emergency department. Due to the difficulty in confirming the appropriate diagnosis clinically. Ultrasound is the initial imaging used for the diagnosis of acute cholecystitis. Gallbladder polyps in the present study representing $1 \%$. While in other study the polyps are relatively frequent, seen in up to $5 \%$ of the population. Over $90 \%$ are benign, and the majority are cholesterol polyps [6]. Ultrasound is the initial investigation of choice as it separate cholesterol polyps from those requiring treatment. The features of gallbladder polyps are a non-shadowing.

Incidence of gallstone was $37 \%$. The ratio of incidence between male to female 1:3 Ultrasonography was founded the technique of choice for diagnosing gallbladder calculi and it was the gold standard test for the demonstration of gallstones with sensitivity of $94 \%$ and a specificity of $92 \%$ [13]. The gallstones are hyperechoic and cause posterior acoustic shadowing in the body while small gravel-like stones less than $5 \mathrm{~mm}$ in diameter may not shadow but will remain hyperechoic [14].

Sonography is excellent in the initial evaluation of jaundiced patients. It differentiated between obstructive and nonobstructive jaundice. Ultrasound is painless and relatively inexpensive, and has several advantages over oral cholecystography; it doesn’t needed contrast material, causes no side-effects, and safe during pregnancy [15]. 
In the present study, acute cholecystities representing $12 \%$ while chronic cholocystities $1 \%$. The presence of gallstones is the primary sonographic appearence for the diagnosis of acute cholecystitis. Gallstones can be present in the setting of acute biliary disease or found incidentally. A gallstone appears as a mobile, hyperechoic focus within the gallbladder, casting an anechoic [16] [17]. Sludge constitute $2 \%$, a dependent layer of nonshadowing echogenicity in the gallbladder is characteristic of sludge, which often contains stones.

\section{Conclusion}

In the study we found the Ultrasound which is non-invasive and the least expensive imaging modality that is highly sensitive and specific in the assessment of the gallbladder wall and luminal content. It can provide information about the presence of GB pathologies such as G. stone choleycystities, Carcinoma of gall bladder, Gallbladder Polyps and moreover about the site and cause of biliary tract obstruction.

\section{References}

[1] Roger, C.S. and Nacy, S.M. (1998) Clinical Sonography. Lippincott, New York.

[2] Strasberg, S.M. (2008) Acute Calculouscholecystitis. New England Journal of Medicine, 358, 2804-2811. http://dx.doi.org/10.1056/NEJMcp0800929

[3] Bennett, G.L. and Blathazar, E.J. (2003) Ultrasound and CT Evaluation of Emergent Gallbladder Pathology. Radiologic Clinics of North America, 41, 1203-1216. http://dx.doi.org/10.1016/S0033-8389(03)00097-6

[4] Rumack, C.M., Wilson, S.R. and Charboneau, J.W. (2005) Diagnostic Ultrasound Volume 1. 3rd Edition, Elsevier Mosby, Philadelphia.

[5] Trowbridge, R.L., Rutkowski, N.K. and Shojania, K.G. (2003) Does This Patient Have Acute Cholecystitis? JAMA, 289, 80-86. http://dx.doi.org/10.1001/jama.289.1.80

[6] Kubota, K., Bandai, Y., Noie, T., et al. (1995) How Should Polypoid Lesions of the Gallbladder Be Treated in the Era of Laparoscopic Cholecystectomy? Surgery, 117, 481-487. http://dx.doi.org/10.1016/S0039-6060(05)80245-4

[7] Laing, F.C. (1991) The Gallbladder and Bile Ducts. In: Rumack, C.M., Wilson, S.R. and Charboneau, J.W., Eds., Diagnostic Ultrasound, Vol. 1. Mosby-Year Book, St. Louis.

[8] Allen-Mersh, T.G., Motson, R.W. and Hately, W. (1985) Does It Matter Who Does Ultrasound Examination of the GB? British Medical Journal, 291, 389 390. http://dx.doi.org/10.1136/bmj.291.6492.389

[9] Huffman, J.L. and Schenker, S. (2009) Acute Acalculous Cholecystitis-A Review. Clinical Gastroenterology and Hepatology, 8, 15-22.

[10] Jeffrey, B. and Ralls, P. (1995) Sonography of the Abdomen. Raven, New York.

[11] Janes, J.O. and Nelson, J.A. (1988) Jaundice. In: Eisenberg, R.L., Ed., Diagnostic Imaging: An Algorithmic Approach, JB Lippincott, Philadelphia.

[12] Bree, R.L. (1995) Further Observations on the Usefulness of the Sonographic Murphy Sign in the Evaluation of Suspected Acute Cholecystitis. Journal of Clinical Ultrasound, 23, 169-172. http://dx.doi.org/10.1002/jcu.1870230304

[13] Theodoro, D. (2007) Hepatobiliary. In: Ma, O.J., Mateer, J.R. and Blaivas, M., Eds., Emergency Ultrasound, McGrawHill, New Delhi, 177-186.

[14] Ralls, P.W., Halls, J., Stewart, L.A., Quinn, M.F., Morris, U.K. and Boswell, W. (2005) Prospective Evaluation of the Sonographic Murphy’s Sign in Suspected Acute Cholecystitis. Journal of Clinical Ultrasound, 10, 113-115. http://dx.doi.org/10.1002/jcu.1870100305

[15] Kendall, J.L. and Shimp, R.J. (2001) Performance and Interpretation of Focused Right Upper Quadrant Ultrasound by Emergency Physicians. Journal of Emergency Medicine, 21, 7-13. http://dx.doi.org/10.1016/S0736-4679(01)00329-8

[16] Ryu, J.K., Ryu, K.H. and Kim, K.H. (2003) Clinical Features of Acute Acalculous Cholecystitis. Journal of Clinical Gastroenterology, 36, 166-169. http://dx.doi.org/10.1097/00004836-200302000-00015

[17] Yeh, H.C., Goodman, J. and Rabinoitz, J.G. (1986) Floating Gallstones in Bile without Added Contrast Matcrial. American Journal of Roentgenology, 146, 49-50. http://dx.doi.org/10.2214/ajr.146.1.49 
Scientific Research Publishing (SCIRP) is one of the largest Open Access journal publishers. It is currently publishing more than 200 open access, online, peer-reviewed journals covering a wide range of academic disciplines. SCIRP serves the worldwide academic communities and contributes to the progress and application of science with its publication.

Other selected journals from SCIRP are listed as below. Submit your manuscript to us via either submit@scirp.org or Online Submission Portal.
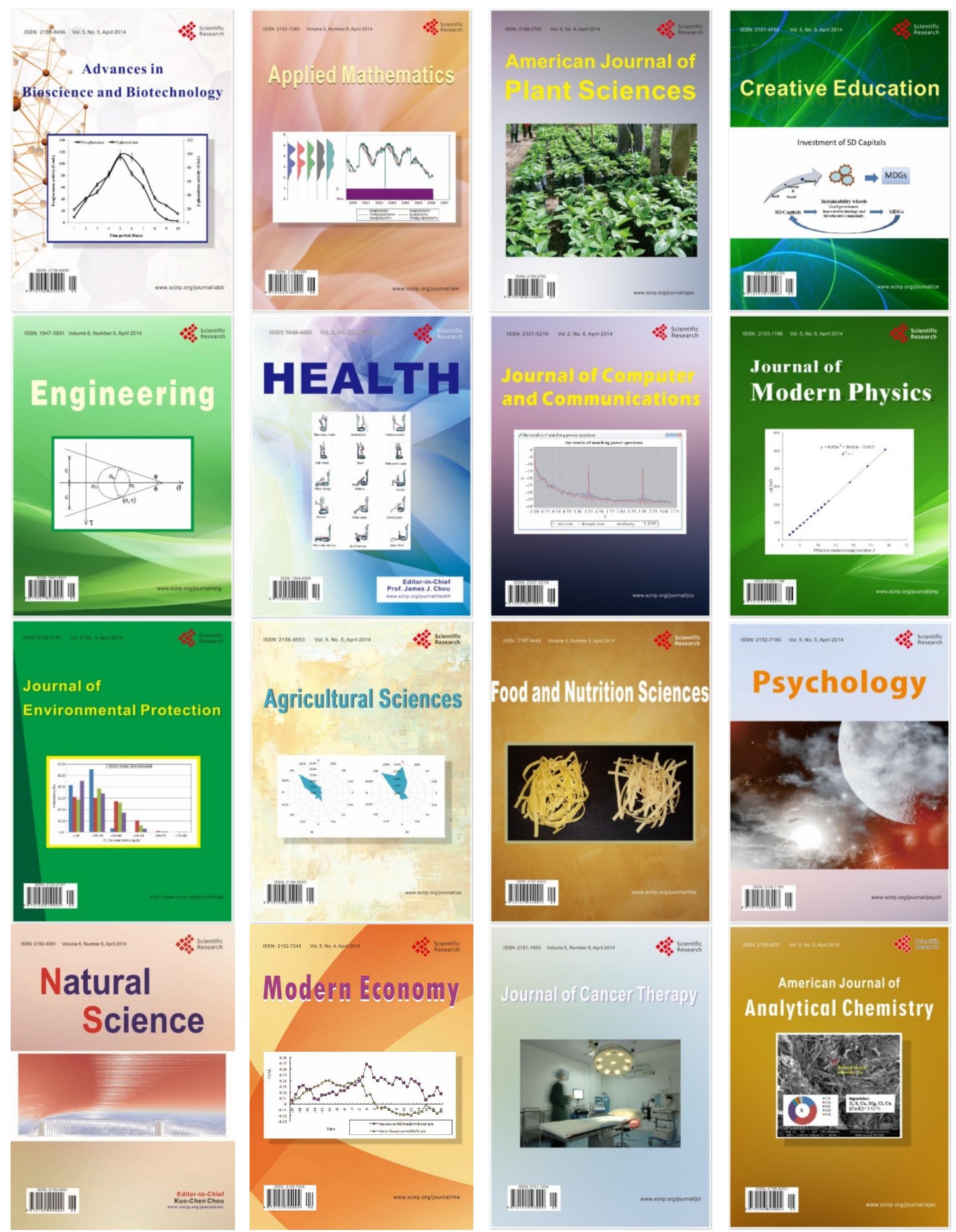